\author{
B.C. Патрушев
}

\author{
АНАЛИЗ ВНЕДРЕНИЯ ИНСТРУМЕНТОВ КОНЦЕПЦИИ \\ БЕРЕЖЛИВОГО ПРОИЗВОДСТВА НА ПРИМЕРЕ \\ ДЕЯТЕЛЬНОСТИ ПРЕДПРИЯТИЯ АО «СОРБЕНТ»
}

\begin{abstract}
Рассмотрены особенности применения методов и инструментов концепции бережливого производства на примере иностранных и отечественных предприятий. Приведены теоретические и практические аспекты методологии. Описан успешный опыт внедрения методов бережливого производства на предприятии АО «Сорбент». Предложены методы повышения экономической составляющей предприятия на основе включения персонала в потоки создания потребительской ценности и повышения личной и групповой ответственности за результаты своего труда через участие сотрудников в рабочих группах. Разработан подход, совмещающий инструменты бережливого производства и процессы модернизации предприятия, проведены работы по автоматизации отдельных рабочих мест. Описан экономический эффект от использования и внедрения инструментов бережливого производства на примере предприятия АО «Сорбент» и динамики его производственных процессов. Отражен наглядный пример увеличения объема производства и объема выпускаемой продукции, уменьшения времени такта и времени сборки отдельных элементов выпускаемой продукции, уменьшения незавершенного производства (НЗП), снижения времени протекания процесса, использования карты потока создания ценностей, структуризация логистики доставки сырья на предприятие, популяризации знаний по увеличению производительности труда сотрудников предприятия и его руководящего состава. В рамках реализации национального проекта «Производительность труда и поддержка занятости» на опытном участке предприятия внедрены инструменты бережливого производства: визуализация, информационные центры, стенд по управлению проектом, а также изменена структура управленческих процессов. Сформулированы проблемы и продемонстрированы пути их решения при реализации принципов бережливого производства на предприятии АО «Сорбент».

Ключевые слова: бережливое производство; экономика; производительность труда; методы и инструменты бережливого производства; эффрективность.
\end{abstract}

Концепция бережливого производства разработана в 1950-х гг. У ее истоков стоял Тайити Оно, при работе в Тоyota Motor он усовершенствовал процессы производства в области машиностроения [1, с. 10]. Последующее рассмотрение методологии бережливого производства пришлось на 1980-е гг., когда Майкл Вейдер отмечал невозможность построения качественных производственных процессов без использования фундаментальных техник и методологий [2, с. 15]. Бережливое производство (БП) должно строиться через взаимодействие современных и традиционных инструментов. В связи с этим целью исследования является анализ эффективности использования концепции бережливого производства, комплекса методов и инструментов в создании и реализации качественных това-

() Патрушев В.С., 2021

Патрушев Владимир Сергеевич - менеджер ОРПС, АО «Сорбент», аспирант кафедры менеджмента и маркетинга ФГБОУ ВО «Пермский национальный исследовательский политехнический университет», e-mail: patrushev94@yandex.ru. 
ров и услуг в запрашиваемые потребителем сроки на примере деятельности предприятия АО «Сорбент». Объект исследования - процессы бережливого производства на предприятии АО «Сорбент».

Проблема реализации эффективного производства привлекает исследователей на протяжении последних десятилетий [3-6]. Анализируя опыт построения бережливого производства на действующих предприятиях, можно оценить перспективы и корректировки в целях усовершенствования и подготовки практичной технологии бережливого производства. Особенность рассмотрения бережливого производства в данной статье заключается в приведении данных производительности труда до и после внедрения концепции бережливого производства в бизнес-процессы АО «Сорбент». Деятельность исследуемого предприятия опирается на разработку подходов, совмещающих методы бережливого производства и модернизацию предприятия для повышения производительности труда.

Анализ применения технологии бережливого производства обусловлен рядом причин [7, с. 27]:

1) изучение опыта действующих бизнес-процессов провоцирует корректировку и создание управленческих методик, изменение траектории развития производства;

2) применение методологии бережливого производства позволяет сохранить объемы производительности при экономическом кризисе и других нестабильных экономических явлениях;

3) эффективность использования методики и технологий бережливого производства прослеживается в историческом аспекте на примере успеха известных мировых компаний во всех отраслях экономики;

4) в методологии БП прослеживается объединение хозяйствования на рынке с административно-командным видом экономики (произведение того, что востребовано с правильной постановкой управленческих целей и решений).

Перед анализом внутренней составляющей бережливого производства на отдельных предприятиях рационально рассмотреть его сущность и положения. В понимании Майкла Вейдера бережливое производство - многосторонняя производственная система, в то же время это философия, подразумевающая планирование рабочего пространства сотрудников, производственных площадей, ремонтной и обслуживающей службы, логистических решений, бухгалтерии, т.е. каждый элемент многогранного производства [8, с. 11].

Производственное совершенствование через разработку методов бережливого производства начато в Японии в 1950 гг. [9, с. 21]. Экономический кризис способствовал разработке методов и технологий БП. Основа заключалась в произведении только тех товаров и услуг, которые имеют максимальную ценность для потребителя, и сокращении затрат на создание таких продуктов. Современная экономическая обстановка также имеет нестабильность, поэтому 
экономистами прогнозируется ограничение ресурсной базы и приоритетность развития концепции бережливого производства. Возникла задача - сократить себестоимость выпускаемой продукции (автомобилей) при повышении спроса и потребностей конечного потребителя.

Реализация концепции БП включает в себя [4, с. 7]:

1. Стратегическое планирование (все бизнес-процессы и управленческие решения направлены на нужды заказчика).

2. Процессы (конкретные действия, направленные на сокращение потерь, непрерывную организацию создания товаров или услуг, планомерное решение проблем).

3. Персонал (организация командной работы, обмен информацией, кайзен и рационализаторство).

В совокупности данные пункты обеспечивают инновационный базис управления, увеличение производительности труда и конкурентоспособности предприятия на мировой арене.

Внедрение инструментов БП имеет поэтапную структуру. Выделены базовые инструменты [10, с. 46]:

- система 5S;

- всеобщий уход за оборудованием (ТPM);

- быстрая переналадка (SMED);

- визуализация (организация информационных стендов);

- «креативная техника» 6-3-5 («brainwriting»);

- анализ эффективности оборудования;

- организация работы с предложениями по улучшению;

- управления запасами;

- построение КПСЦ.

Японская компания Toyota эффективно внедрила БП в деятельность предприятия. Главный тезис философии компании заключается в полной, многогранной трансформации культуры ведения производства. Для достижения эффективности производства потребовалось полное изменение мышления и культуры управляющего персонала, сотрудников [1, с. 42].

Шведская компания Volvo для организации деятельности заводов использует систему производства «Volvo Production System», основой которой является БП. Параллельно с этим компания Volvo применяет систему качества аудит готовой продукции. Американская компания Crandon Corporation провела ряд исследований и обсуждений, опирающихся на принципы бережливого производства. Их деятельность показала, что использование тянущей системы (pull system) [8, с. 34], визуального управления (visual management), стандартизации работы и безопасности (standardize work and safety), постоянного стремления к улучшению (kaizen) [9, с. 57] положительно влияют на повышение эффективности бизнес-процессов компании, а также на снижение затрат. 
Немецкая компания Hellmann East Europe для усовершенствования процессов складирования и международных перевозок использовала концепции, основанные на БП: just-intime; just-in-sequence delivery to production lines; flow-charts; schedules emergency plans per business/customer. Включение данных концепций в политику компании увеличило доход предприятия до 19,6 млн евро на 2011. На сегодняшний день компания опирается на данные принципы и приумножает доход, проводя рефлексию деятельности предприятия, его финансового состояния, потребностей компании, технологий процессов и всех внешних и внутренних проблем, с которыми компания встречалась когда-либо.

В ряде российских компаний успешное применение концепции БП анализируется по следующим показателям [4, с. 6; 11, с. 225]:

1. Компания результативна, если во главе управленческого персонала стоит топ-менеджер.

2. В процесс достижения целей вовлечены все сотрудники компании.

3. Компания заинтересована в систематической повышении квалификации всех сотрудников, способствует развитию лидерских качеств и их роли в реализации БП.

4. Пересмотр ведения производственных процессов начинается с пилотных проектов. На их примере сотрудники видят значимость каждого в общей структуре.

5. Закрепление достигнутых результатов как нормы и проектирование перспективы развития предприятия.

На территории Российской Федерации знания об основах бережливого производства проникли в социальные сети, в иные электронные ресурсы. К таким относятся: Институт комплексных стратегических исследований (ИКСИ), Блог о производственном менеджменте «Leaninfo.ru», Межрегиональное общественное объединение «Союз Бережливых», Деловой портал «Управление производством», ITеат-портал - Технология корпоративного управления, Стандарты и качество, «Управляй будущим», Ассоциация Деминга, Линфорум, Блог об образовании EquipNet.ru и др.

Для формирования перспективной культуры предприятия управление им должно сводиться к созданию конкурентоспособной культуры. Это, в свою очередь, должно повышать производительность труда и удерживать предприятие на мировой арене. Создание конкурентоспособной культуры сводится к формированию совокупности специфических свойств структуры предприятия, отражающей конкурентные преимущества через поиск и реализацию способов удовлетворения потребностей конечных потребителей [5, с. 19]. Конкурентоспособность является одним из существенных показателей развития предприятия в правильном русле. Если предприятие конкурентоспособно, значит, оно сможет существовать в экономической сфере долгое время. Задача управлен- 
ческого состава сводится к постоянному поиску новых путей развития предприятия, новых потребностей потребителя.

Несмотря на перенятый опыт западных компаний, российское производство стремится использовать лин-методологии в установке внутренней политики компаний. БП на российских площадках успешно применено компанией ОАО «КамАЗ» [4, с. 3]. Первое, на что следует обратить внимание, это проведение обучения персонала каскадным способом (передача знаний происходит постепенно от аналитической службы к топ-менеджерам, от них до сотрудников других должностей) [12, с. 18]. Второе - выстраивание производственной системы имеет спиралевидную структуру из 4 пунктов [3, с. 8]:

1. Перспективное планирование с введением стандартов культуры сотрудников и системой мотивации.

2. Пересмотр бизнес-процессов, в том числе входящих элементов производственного управления.

3. Адаптация взаимодействия с поставщиками.

4. Увеличение процессов производственной среды в сервисных центрах.

Третье - обеспечение коммуникаций между сотрудниками через рабочие группы. На данных группах формируются готовые решения по производству и реализации продукции (в том числе закупка сырья) [13, с. 644]. Эффективный инструмент деятельности рабочей группы - карта потока создания ценностей (КПСЦ). Ее составление, рассмотрение и корректировка обеспечивают пересмотр ценностей деятельности предприятия на философском уровне, а также для каждого сотрудника. C ее помощью можно рассмотреть предназначение предприятия на всех уровнях торговли и бизнеса, a также поиск решения при возникновении проблемной ситуации. При решении организационной или иной проблемы при вовлечении всей команды можно достичь эффективных результатов, так как команда ищет решение, а не принимает готовой ответ от одного сотрудника.

Успешный опыт внедрения концепции бережливого производства на зарубежных и отечественных предприятиях наглядно демонстрирует эффективность ее применения [14, с. 75], что обусловливает необходимость внедрения БП в деятельность предприятия АО «Сорбент».

Деятельность предприятия АО «Сорбент» заключается в производстве средств индивидуальной защиты, активированного угля (более 40 торговых марок), коагулянтом, систем подготовки и очистки воды. Среднесписочное количество работников на 2019 г. составило 1200 человек. Одно из наиболее популярных направлений в настоящее время - это выпуск панорамных масок для защиты органов дыхания. Панорамные маски серии МАГ и UNIX предназначены для использования в составе фильтрующих промышленных противогазов «Рубеж», «ДОТ», «ДОТпро», «ДОТм», «UNIX». Панорамные маски соответствуют ГОСТ 12.4.293-2015. Маски снабжены узлами подсоединения 
фильтров «байонетного» и резьбового типов, к которым подсоединяются противогазовые, противоаэрозольные и комбинированные фильтры.

Особенность организации производства заключается в том, что отдельные операции трудоемки и требуют длительных временных и производственных затрат. До потребителя и предприятий реализации доходит качественная продукция, при том, что объем выпускаемой продукции не максимален. Введение БП позволило увеличить производительность труда (соответственно и объем выпускаемой продукции при сохранении качества).

Бизнес-процессы компании АО «Сорбент» с 2012 г. имеют тенденцию применения успешного опыта БП. В 2017 г. Президентом РФ поставлена задача - обеспечить рост производительности труда не ниже 5 \% к 2024 г. на средних и крупных предприятиях несырьевых отраслей экономики. Первым этапом решения поставленной задачи стало создание Национального проекта «Производительность труда и поддержка занятости» [15].

Результаты достижения основных положений концепции:

- применение эффективных мер увеличения производительности труда;

- популяризация знаний и умений повышения производительности труда;

- мотивация стремлений к повышению производительности труда предприятиями, а также всех уровней органов власти.

Для достижения запланированных результатов в 2017 г. был создан АНО «Федеральный центр компетенций в сфере производительности труда». Основные задачи ФЦК [16, с. 3]:

1. Планирование действий по реализации задач проекта и проведение контроля за их исполнением.

2. Подбор предприятий-участников для участия в Национальном проекте.

3. Содействие предприятиям для эффективной результативности идей проекта.

4. Проведение скрининга итогов участия в проекте в соответствии с перечнем положений о выделении финансовой помощи.

5. Систематический отчет об этапах участия в проекте в органах власти, общественных организациях и бизнес-секторе.

Участие в данном Национальном проекте стимулирует предприятия решать производственные и управленческие вопросы через внедрение концепции бережливого производства.

В рамках реализации Национального проекта «Производительность труда и поддержка занятости» в декабре 2017 г. исследуемое предприятие АО «Сорбент» подписало соглашение об участии в проекте. Для предприятия приоритетным направлением стало внедрение в бизнес-процессы концепции бережливого производства. В качестве «учения о понятии» приведем определение понятия «бережливое производство». Бережливое производство (в переводе с англ. «lean production, lean manufacturing») - это учение об управленческих решениях произ- 
водственного предприятия, направленных на снижение затрат во всех сферах проявления [17, с. 4]. Основные цели БП - привлечение к задачам предприятия всех сотрудников организации, повышение конкурентоспособности выпускаемой продукции, ориентированность конечного продукта на запросы потребителя. Эффективное бережливое производство строится на увеличении производительности предприятия при минимальном вовлечении трудовых единиц.

В 2017 г. министерство промышленности, предпринимательства и торговли Пермского края совместно с Минэкономразвития организовало обучение практическим инструментарием производственной системы «Росатом». Для этого из 6 предприятий были выбраны рабочие группы. На протяжении двух недель происходило обучение теоретическим и практическим навыкам, которые были реализованы в производственной системе «Росатом». От исследуемого предприятия АО «Сорбент» в данном мероприятии приняла участие рабочая группа в составе четырех человек.

Применение методологии бережливого производства позволило пересмотреть организационную структуру предприятия [18, с. 322]. Таким образом, по завершении обучения каждая рабочая группа обязана реализовать инструменты, которые были получены. Такой подход позволил расширить число участников рабочих групп в пределах предприятия и увеличить объем времени, затрачиваемого на реализацию поиска новых подходов к управлению и совершенствованию производства. Рабочие группы предприятия АO «Сорбент» на данный момент состоят из представителей производственных цехов и сотрудников научно-технических служб, начавших работу на предприятии во второй половине декабря 2017 г.

После эффективного применения технологии рабочих групп был организован отдел развития производственной системы (РПС). Его первичная задача состояла в отборе пилотного участка - образца активной реализации концепции бережливого производства. Критерии отбора:

- участок с локализованными скрытыми потерями;

- участок конечный в процессе сборки;

- на участке все операции цикличны;

- на участке необходимо увеличение выпуска продукции.

Для выбранного участка подготовлена «карточка» проекта. В ней содержится следующая информация:

1. Ответственные и вовлеченные лица, его границы. В том числе периметр процесса, владелец, руководитель, команда. Отдел развития производственной системы состоит из заказчика проекта - генерального директора, руководителя проекта - начальника цеха, куратора проекта - начальника РПС.

2. Обоснование необходимости реализации проекта на данном участке, его ключевые риски. Выбранный участок считается «узким» местом, так как на нем возможна демонстрация устранения потерь, проецируется потенциально развитая производственная система, осуществляется ручная сборка элементов. 
3. Цели и плановые показатели достижения результата:

3.1. Прирост объема готовой продукции;

3.2. Сокращение ручного труда и количества незавершенных единиц;

3.3. Уменьшение затрат времени сотрудников на сборку единиц продукции;

3.4. Увеличение объема выработки на одного человека без сокращения рабочих единиц.

4. Ключевые мероприятия по внедрению концепции БП:

4.1. Начало проекта;

4.2. Анализ текущего и планируемого состояния участка: описание начального состояния процесса, производственный анализ, разработка карты планируемого состояния участка;

4.3. Реализация концепции. Совещание участников проекта по защите и корректировке предлагаемых решений;

4.4. Закрепление полученных результатов, их рефлексия. Закрытие проекта. Производственный анализ, анализ результатов участниками проекта.

Последующая деятельность руководителей проекта сводится к составлению карты потока состояния ценностей (КПСЦ) текущего и планируемого состояния. Составление карты опирается на философию БП, основа которой заложена в потоке создания ценности для потребителя. Деятельность, переданная через операцию или процесс в результат и продукт, должна сводиться к созданию потока прямых или косвенных ценностей. В концепции БП отражено стремление увеличить скорость создания ценностей, обеспечение непрерывности и равномерности производственных процессов без потерь [19, с. 285]. С этой точки зрения идеальной моделью создания потока ценностей можно считать множество единичных изделий. Полноразмерное выстраивание всех процессов, операций деятельности предприятия в виде нескончаемого потока ценностей является универсальной моделью увеличения эффективности и производительности [20, с. 9]. Построение КПСЦ делает наглядными факторы увеличения время протекания процесса (ВПП) и незавершенное производство (НЗП). Котировка данных факторов позволяет решить следующие задачи:

1) устранение внешних и внутренних провокаторов увеличения ВПП;

2) соответствие установленному таймингу;

3) экономия материальной базы, средств, уменьшение себестоимости выпускаемой продукции;

4) оперативное реагирование на возникающие проблемы.

На предприятии АО «Сорбент» при создании КПСЦ проведены:

1. Анализ текущего состояния производительности, сбор совокупной информации о потоке, детализация данных о проводимых процессах и операциях.

2. Разработка эталона положения потока, основанного на лучших практиках организации производственных процессов.

3. Сравнительный анализ текущего состояния и эталона. 
4. Проектирование эталона состояния потока с учетом имеющихся средств и ресурсов для ведения проекта.

5. Формирование поэтапного списка мероприятий по переходу от текущего состояния до эталона.

Диагностика и скрининг всех потенциальных проблем на участке позволили составить список решений, которые повлияли на результативность реализации проекта. Далее приведем наглядный анализ решения проблемных ситуаций, а также показатели улучшения деятельности предприятия при внедрении концепции БП в рамках реализации национального проекта.

Перечень анализируемых мероприятий, выявленных проблем и их решение представлен в таблице.

После реализации мероприятий, направленных на оптимизацию работы участка, автором проанализирована динамика изменений относительно одного года (рис. 1-3).

На рис. 1 автором показано, что с апреля 2018 г. произошло резкое сокращение времени на прохождение процессов. Данное явление объясняется принятием в этот период решения о преобразовании рабочего участка и потока единичной продукции. С августа по декабрь 2018 г. виден спад, что связано с организацией ежесменного завоза комплектующих на участок (данное решение представлено в таблице).

На рис. 2 виден прирост выработки участка сборки на 86 \% относительно декабря 2017 г. Данное увеличение обусловлено:

1) изменением политики передачи продукции с помощью поворотного стола на электроприводе;

2) автоматизацией рабочего места и исключением дублирующих операций.

На рис. 3 в динамике НЗП наблюдается плавный спад единиц незавершенного производства (с декабря 2017 г. по декабрь 2018 г. сокращение единиц НЗП в 3 раза). Это можно объяснить эффективной организацией потока единичных изделий. При применении БП на данном этапе детали не складируются на одном этапе производства, а передаются на последующие этапы.

Важно отметить, что в рамках реализации проекта в производство был внедрен один из инструментов БП - визуализация. Таким образом, создалась необходимость в организации информационных центров. В пределах проекта информационные центры выполняют функционал визуального менеджмента производственно-экономических и управленческих процессов, позволяющих своевременно выявить проблемные места и принять управленческие решения через совещания участников проекта и обеспечения коммуникаций сотрудников (рабочие группы) [12, с. 643]. Такая установка направлена на создание качественных каналов реагирования всех участников обеспечения производственных процессов. 


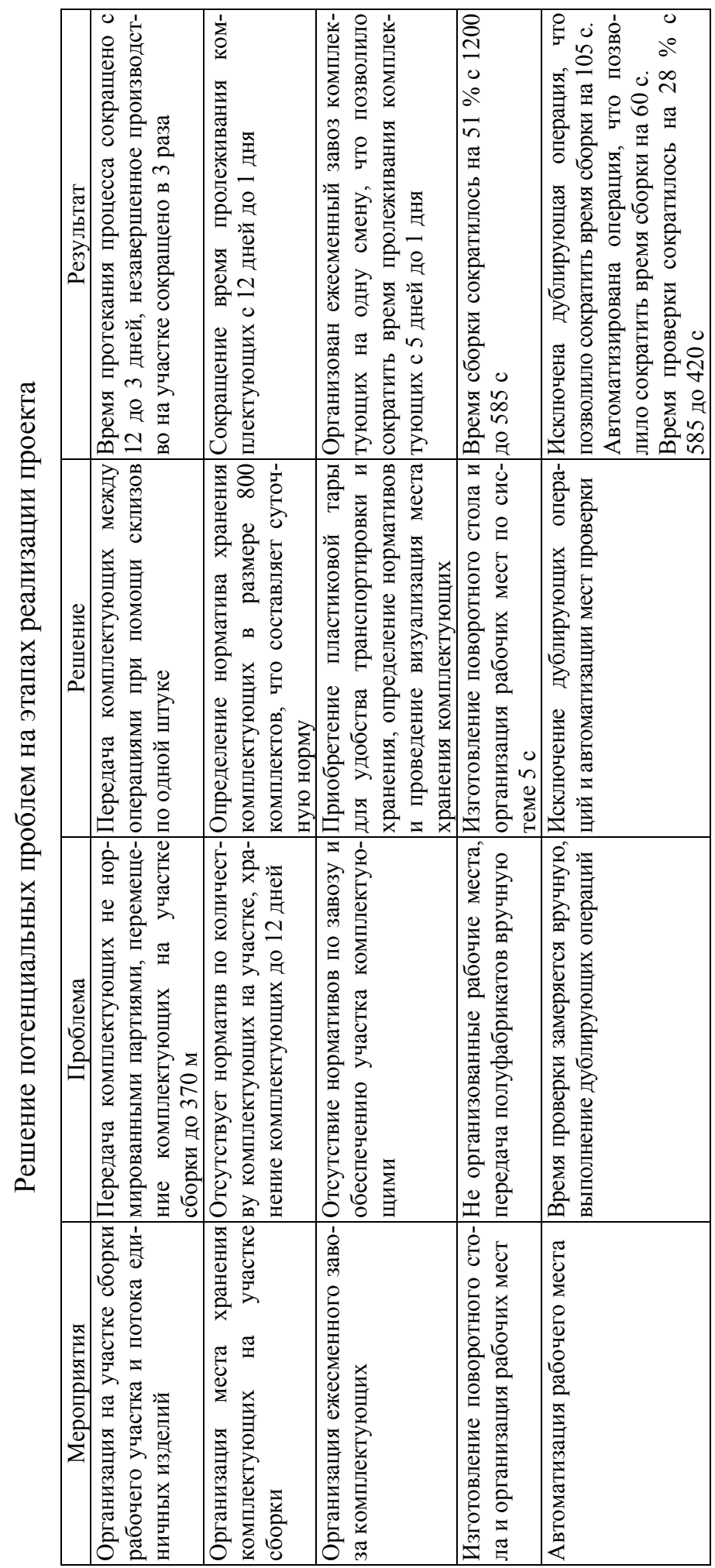




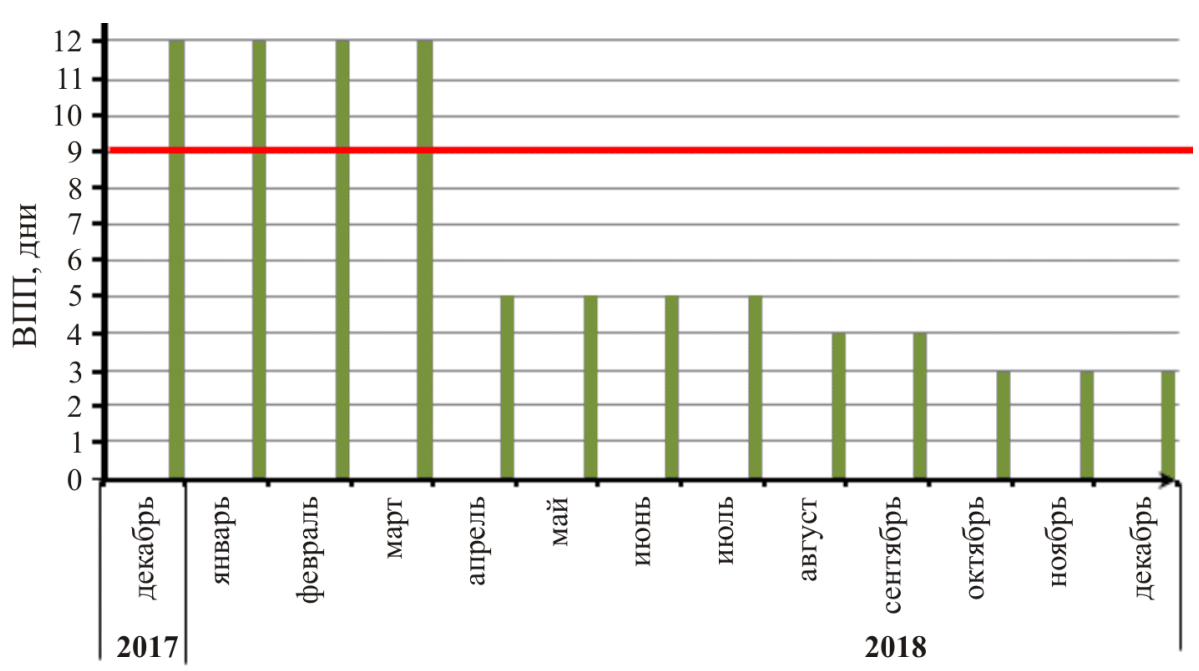

Рис. 1. Динамика ВПП потока производства

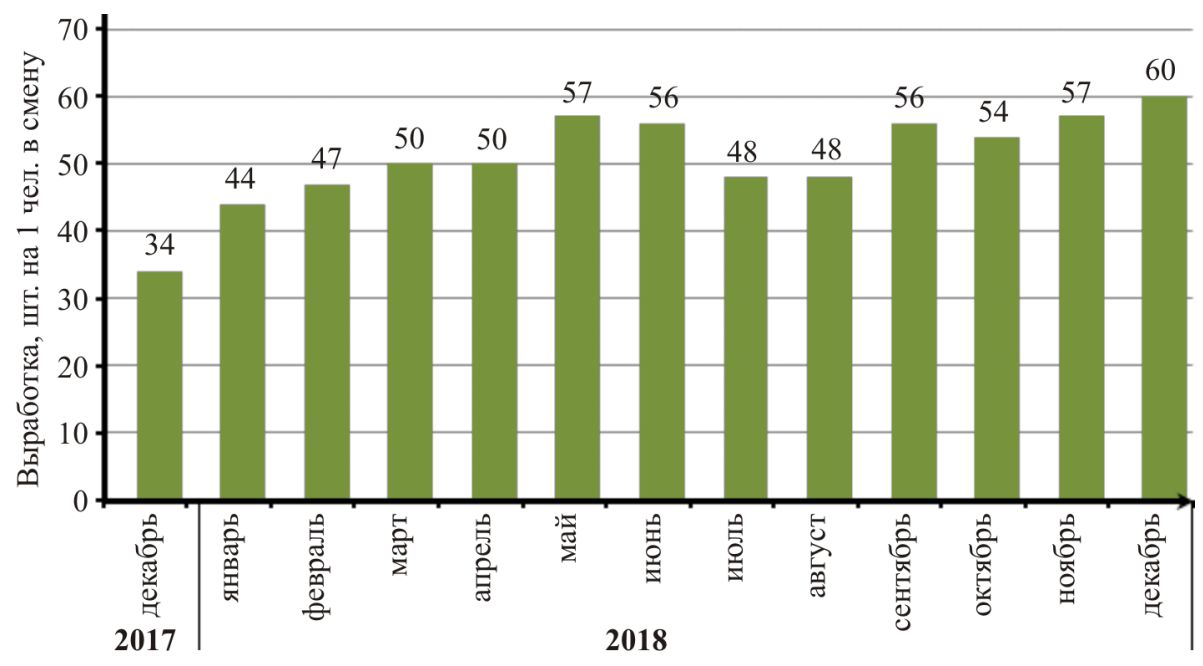

Рис. 2. Динамика выработки участка сборки

Через призму бережливого производства инфоцентры реализуют визуализацию всех явлений, которые рознятся по сравнению с ключевыми показателями деятельности и заданного эталона, идентифицируют проблемные ситуации и ликвидируют потери. Это объясняется принятием эффективных управленческих решений и всеобъемлющего визуального контроля. Центральное звено в создании инфоцентров отводится фокусированию руководителей на проблематике, что способствует быстрой реакции на возникающие проблемные ситуации и риски. Это возможно только через обеспечение эффективной коммуникации всех участников производственного процесса или ответственных лиц за этапы реализации в едином информационном пространстве. 


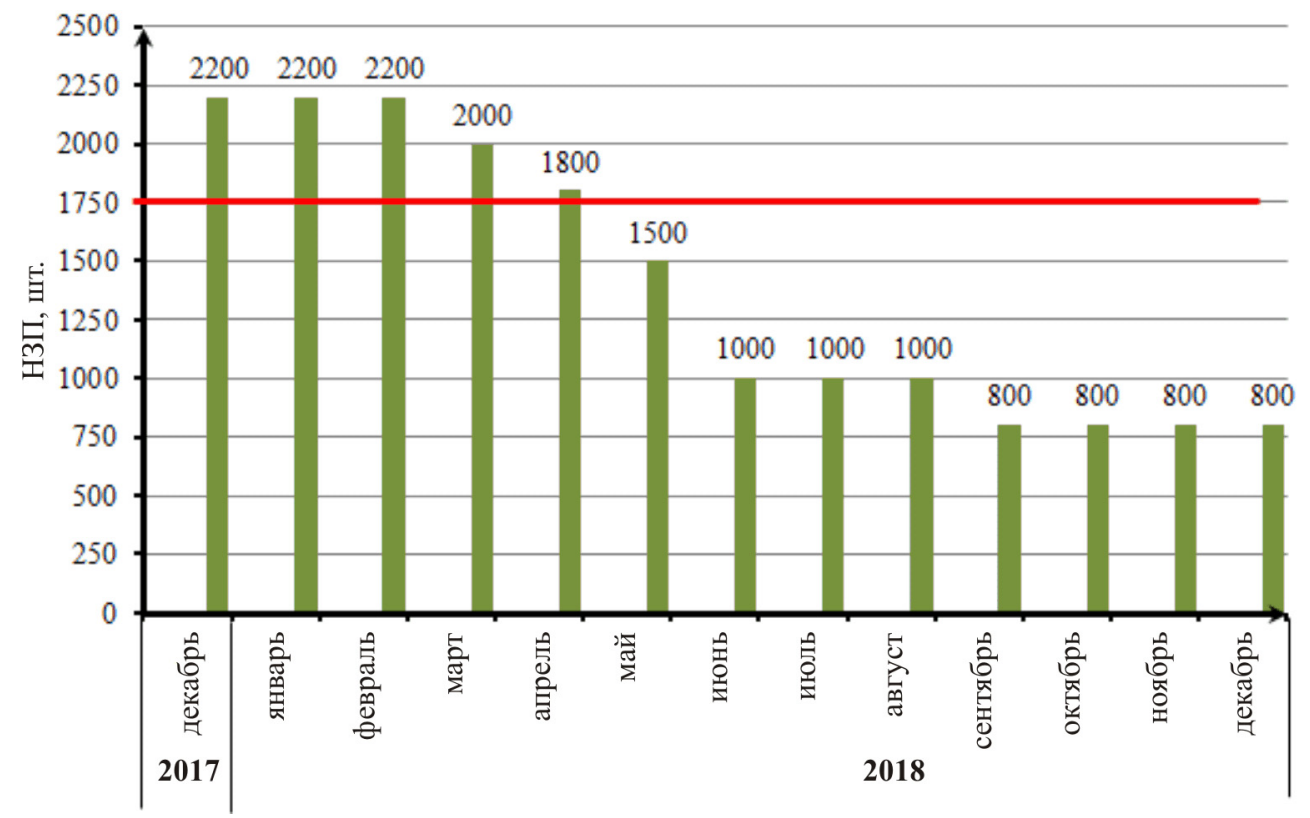

Рис. 3. Динамика НЗП в потоке производства

При создании стендов инфоцентров создается равная возможность информатизации работников. Каждый стенд имеет обязательную унификацию по содержанию для всех уровней управления. Помимо общей информации на стенде принято размещать информацию об обеспечении безопасности, качества, статистики исполнительности по заказам и количестве полученных затрат, об основах корпоративной культуры и этики.

\begin{tabular}{|c|c|c|c|c|c|c|}
\hline & 1 & 2 & 3 & \multirow[b]{3}{*}{12} & \multirow[b]{3}{*}{13} \\
\hline & & 4 & 5 & 6 & & \\
\hline 7 & 8 & 9 & 10 & 11 & & \\
\hline 14 & 15 & 16 & 17 & 18 & 19 & 20 \\
\hline 21 & 22 & 23 & 24 & 25 & 26 & 27 \\
\hline & & 28 & 29 & 30 & & \\
\hline & & & 31 & & & \\
\hline
\end{tabular}

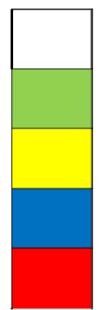

Выходной

День 6ез ТOC

Травмоопасная ситуация

Нарушение

пром.безопасности

Несчастный случай

\begin{tabular}{|c|c|c|c|c|c|}
\hline Дala & Приччнна & Mepellpranase & CPek & Оөвегінененый & Cla w: \\
\hline & & & & & \\
\hline & & & & & \\
\hline & & & & & \\
\hline & & & & & \\
\hline & & & & & \\
\hline & & & & & \\
\hline
\end{tabular}

Дата:

Ответственный:

Рис. 4. Информационный стенд «Безопасность» пилотного участка 
В рамках реализации проекта на предприятии подобный стенд был организован на пилотном участке. Информация, размещенная на стенде, представлена на рис. $4-8$.

\section{Сдача готовой продукции с первого предъявления}

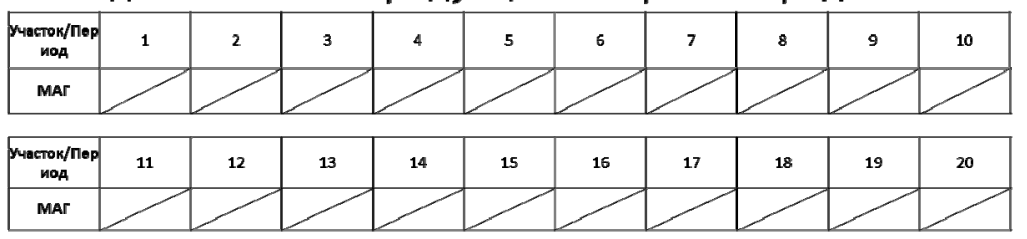

\begin{tabular}{|c|c|c|c|c|c|c|c|c|c|c|c|}
\hline $\begin{array}{c}\text { Участок/Пер } \\
\text { иод }\end{array}$ & 21 & 22 & 23 & 24 & 25 & 26 & 27 & 28 & 29 & 30 & 31 \\
\hline MAT & & & & & & & & & & & \\
\hline
\end{tabular}

\begin{tabular}{c|c|c|c|c|c|}
\hline Дата & Прнчнна & Мероприятие & Срок & Ответственный & Статус \\
\hline & & & & & \\
\hline & & & & & \\
\hline & & & & & \\
\hline & & & & & \\
\hline
\end{tabular}

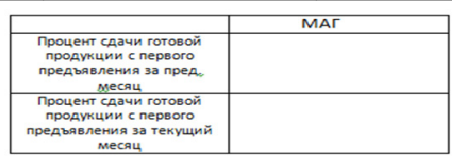

Отвественный:

Рис. 5. Информационный стенд «Качество» пилотного участка

\section{Затраты}

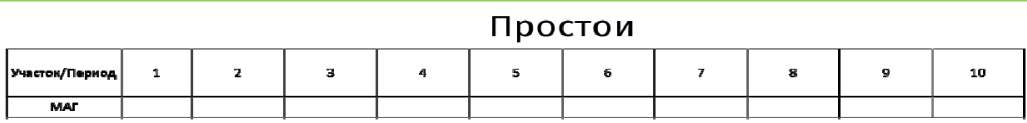

\begin{tabular}{|c|c|c|c|c|c|c|c|c|c|c|}
\hline Yumerow/חapuon & 11 & 12 & 13 & 14 & 13 & 1.5 & 17 & 18 & 19 & 20 \\
\hline Mar & & & & & & & & & & \\
\hline
\end{tabular}

\begin{tabular}{|c|c|c|c|c|c|c|c|c|c|c|c|}
\hline Xyactom/nepuop & 21 & 22 & 23 & 24 & 25 & 26 & 27 & 28 & 29 & 30 & 31 \\
\hline Mar & & & & & & & & & & & \\
\hline
\end{tabular}

\begin{tabular}{|c|c|c|c|c|c|}
\hline בars & Приямна & Merponpersme & Gpons & Отвотстьеннынй & CTatyc \\
\hline & & & & & \\
\hline & & & & & \\
\hline & & & & & \\
\hline & & & & & \\
\hline & & & & & \\
\hline & & & & & \\
\hline & & & & & \\
\hline & & & & & \\
\hline
\end{tabular}

Отвественный:

Рис. 6. Информационный стенд «Простои» пилотного участка 


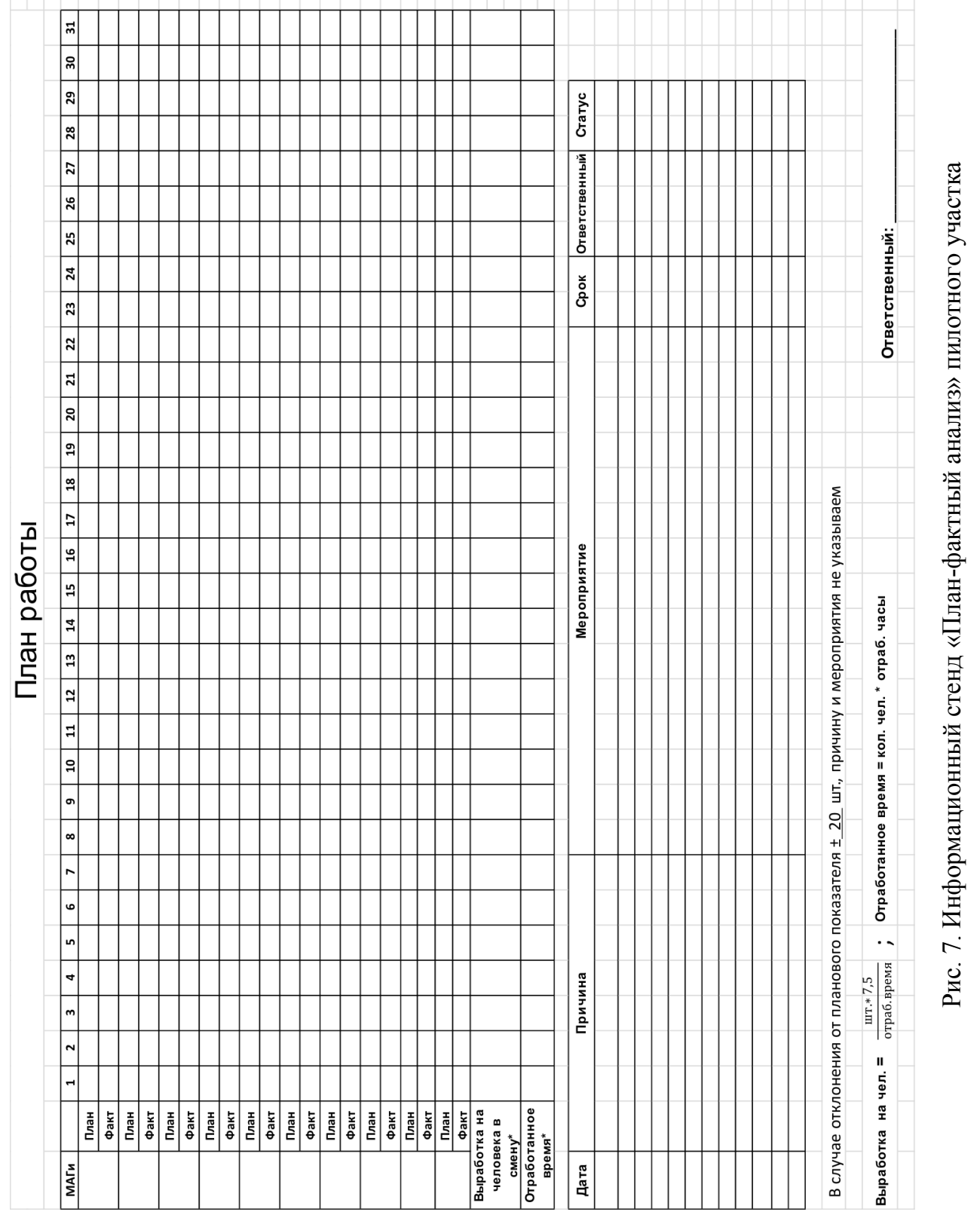



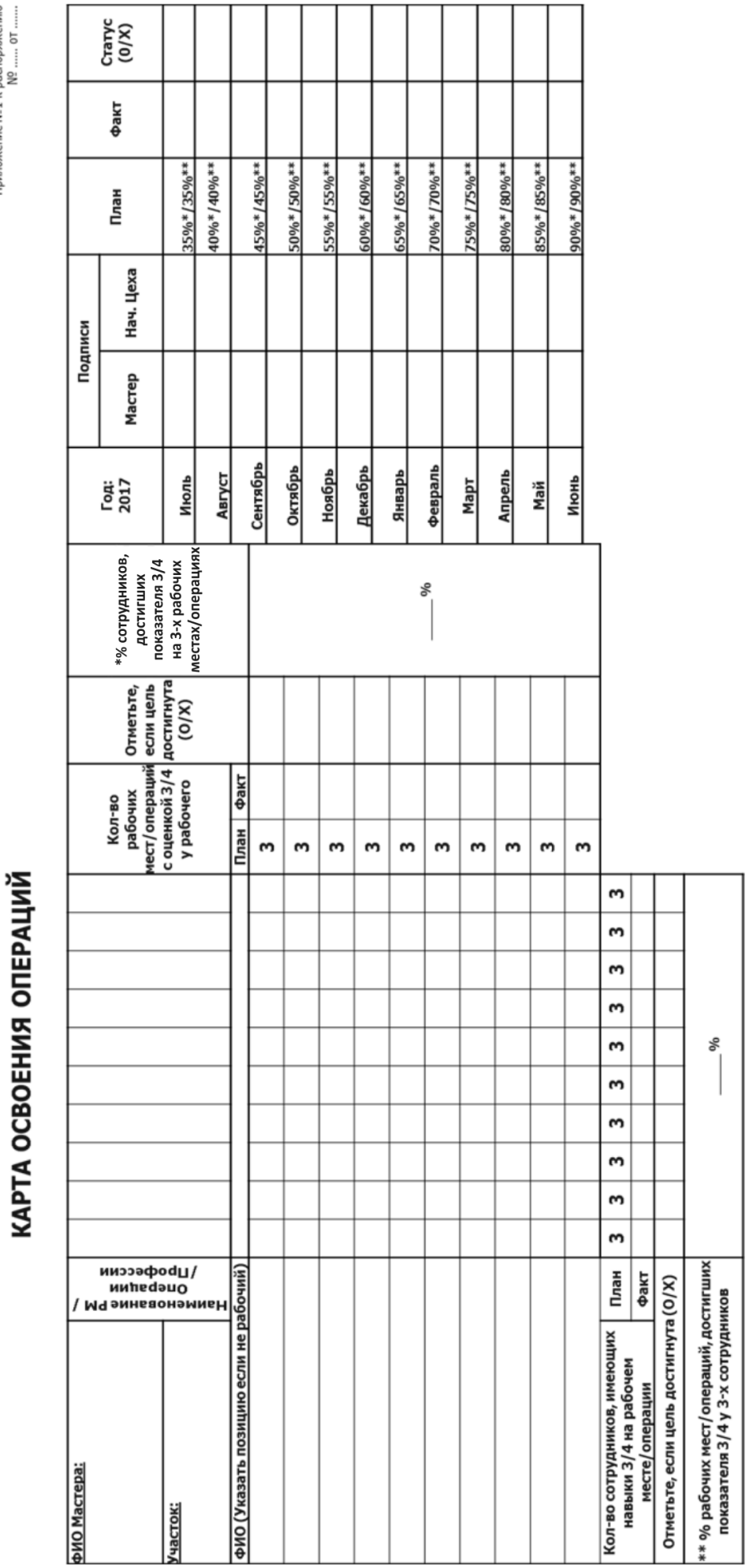
Помимо создания информационных стендов, были приняты меры по организации центров цехового уровня и информационный центр под руководством генерального директора, а также в систему внедрен скрининг почасового производства. Последнее мероприятие позволило обнаружить проблему, замедляющую системные процессы. Это срыв поставок комплектующих элементов продукта. Завершающим мероприятием по организации БП через создание информационных продуктов стало создание стенда по управлению проектом. Содержание стенда:

1. Список рабочей группы проекта (контакты).

2. Утвержденная карточка проекта.

3. Карта процесса текущего состояния.

4. Производственный анализ.

5. Карта процесса целевого состояния.

6. Результаты анкетирования.

7. Перечень проблем с коренными причинами их возникновения, примеры 8D и т.п.

8. План мероприятий.

В рамках проекта и реализации концепции бережливого производства на предприятии АО «Сорбент» дополнительно проведены мероприятия, направленные на достижение планируемых результатов: организована система $5 \mathrm{~S}$ на каждом рабочем месте. Это было отражено в создании стандартов рабочих мест и инструкций для обеспечения рабочих процессов. Проведена структуризация мест по проведению сборки изделий, отбалансировано состояние потока, исключены дублирующие операции. Комплексное внедрение мероприятий по БП принесло положительные результаты: снижен процент брака с 4,8 до 2,3 \%, сокращено время простоя за счет автоматизации рабочих мест и параллельного выполнения упаковки продукции (с 60 до 15 секунд). Комплектация была времязатратным процессом, усовершенствование произошло путем внедрения способа передачи комплектующих посредством склизов, а именно:

- поступление комплектующих полным комплектом, рассчитанным на 1 смену;

- на рабочее место поступает объем комплектующих, рассчитанный на 1 час работы.

В заключение следует отметить, что внедрение концепции бережливого производства в организационные процессы предприятия АО «Сорбент» позволило увеличить эффективность и сократить время создания готовой продукции с сохранением рабочих единиц. На предприятии стандартизирована работа транспортировщика, а именно: модифицирована схема складирования комплектующих элементов на участке, введен обязательный резерв в виде запасных комплектующих, улучшена динамика производства через логистические решения завоза материала на участок, пополнены комплектующие единицы на каждом рабочем мес- 
те. Бережливое производство не следует понимать как инструмент, защищающий предприятие от потерь. Прежде всего это методология выхода производства из экономического застоя, который циклически охватывает все экономики мира. На сегодняшний день мировая экономика находится в состоянии экономического кризиса, поэтому бережливое производство становится востребованным для поддержания бизнес-процесса в эффективном состоянии [4, с. 5].

Сущность вышеизложенного сводится к тому, что не следует всю ответственность за введение эффективного производства перекладывать на концепцию бережливого производства. Задачи модернизации предприятий должны строиться при взаимодействии методологий и инструментов, предлагаемых передовыми исследователями. На российском рынке инструменты бережливого производства работают на сокращение себестоимости и цены только в том случае, если российские производства находятся в относительно равных экономических и технологических условиях с зарубежными предприятиями. Важно отметить роль философии бережливого производства. Предприятию «следует» проникнуть в «боли» и потребность целевого потребителя, проанализировать технологические возможности, готовность внешних и внутренних ресурсов. Объективная оценка позволит выявить пласт действий по модификации предприятия и адаптировать его функционал под потребителя. Это невозможно без преобразования внутренней культуры предприятия.

При анализе внедрения бережливого производства в деятельность предприятия АО «Сорбент» выявлены положительные результаты:

1. Приняты эффективные меры по увеличению производительности труда.

2. Увеличен объем выпускаемой продукции и усовершенствован процесс сборки продукции.

3. Структурирована логистика доставки на предприятие сырья.

4. На предприятии популяризированы знания по увеличению производительности труда. Сотрудниками в увеличенном объеме производится качественная продукция, они понимают, что их труд важен, и могут повлиять на личную эффективность на предприятии.

5. На своем примере АО «Сорбент» демонстрирует важность мотивации к увеличению производительности труда для руководителей других предприятий, а также муниципальных и региональных органов власти.

6. Изменена структура ведения управленческих процессов на опытном участке предприятия (введение деятельности информационного центра, стендов).

Тщательное стратегическое планирование и обоснованное применение методологии бережливого производства приумножит получаемый капитал, а также увеличит возможность конкурировать на мировой торговой арене. При развитии российских предприятий важно учитывать научно-технологический уровень, а также способы и навыки управления бизнес-процессами. Концепция бережливого производства способна увеличить возможность правильного совершенствования именно бизнес-процессов. 


\section{Список литературы}

1. Монден Я. «Тоуота». Методы эффективного управления / пер. с англ. под ред. А.Р. Бенедиктова, В.В. Мотылева. - М.: Экономика, 1989. - 228 с.

2. Вэйдер М. Инструменты бережливого производства. Минируководство по внедрению методик бережливого производства: пер с англ. М.: Альпина Паблишер, 2015. - 116 с.

3. Абросимова А.А. Развитие методов бережливого производства на промышленных предприятиях: автореф. ... канд. экон. наук. - Н. Новгород: Изд-во ННГУ, 2013. - $23 \mathrm{c.}$

4. Клочков Ю.П. Применение концепции Lean для повышения производительности труда на примере ОАО «КамАЗ» [Электронный ресурс] // Международный Лин-форум «Эффективные процессы - высокая производительность». - Казань, 2011. - URL: https://docviewer.yandex.ru/view/935952/?* (дата обращения: 20.09.2020).

5. Пантелеев Д.Н. Обеспечение конкурентоспособности предпринимательских структур на основе конкуренции бережливого производства: автореф. дис. .... канд. экон. наук / Ин-т экономики УрО РАН. - Ижевск, 2007. - 24 с.

6. Шиляева Е.В. Оценка повышения конкурентоспособности российских промышленных предприятий при внедрении системы бережливого производства: автореф. дис. ... канд. экон. наук. - М.: Изд-во НИУ ВШЭ, 2017. - 31 с.

7. Болтачева Н.Р. Бережливое производство как метод повышения эффективности производства на предприятии // SCIENCE TIME. - 2015. - № 8 (20). C. 26-29.

8. Вумек Дж.П., Джонс Д.Т. Бережливое производство. Как избавиться от потерь и добиться процветания вашей компании: пер. с англ. - М.: Альпина Паблишер, 2011. - 473 с.

9. Масааки Имаи. Кайдзен. Ключ к успеху японских компаний: пер. с англ. - М.: Альпина Паблишер, 2011. - 341 с.

10. Климочкин Д.А., Панявина М.Л. Особенности применения концепции бережливого производства в российских условиях / Современное управление: проблемы, тенденции и перспективы: материалы Всерос. науч.-практ. конф. - Тамбов, 2018. - С. 44-49.

11. Калинина К.Р. Бережливое производство как инструмент организации управления производством // Актуальные проблемы авиации и космонавтики. 2015. - № 11. - С. 224-226.

12. ГОСТ Р ИСО 10006-2005: Руководство по менеджменту качества при проектировании / Федер. агент. по техн. регулированию и метрологии. - М., 2007. $-41 \mathrm{c}$.

13. Канюкова В.П. Бережливое производство: основные инструменты и принципы бережливого производства // Аллея науки. - 2018. - № 7 (23). C. 642-647. 
14. Сурикова Е.А. Повышение эффективности деятельности структурного подразделения железнодорожного транспорта на основе принципов бережливого производства // Проблемы экономики и менеджмента. - 2015. - № 1 (41). - С. 73-79.

15. Национальный проект «Производительность труда и поддержка занятости» (протокол от 24 сентября 2018 г.) [Электронный ресурс]. - URL: https://www.economy.gov.ru/material/directions/nacionalnyy_proekt_proizvoditelno st_truda_i_podderzhka_zanyatosti/ (дата обращения: 20.09.2020).

16. Устав Автономной некоммерческой организации «Федеральный центр компетенций в сфере производительности труда»: утв. решением Наблюд. совета АНО «Федеральный центр компетенций в сфере производительности труда» (протокол заседания от 11.12.2019). - М., 2019. -15 с.

17. ГОСТ Р 56020-2014. Национальный стандарт Российской Федерации. Бережливое производство. Основные положения и словарь / Росстандарт. - М., 2014. $-32 \mathrm{c}$.

18. Ермашкевич Н.С. Профиль бизнеса компании и активы, его составляющие // Современные проблемы науки и образования. - 2013. - № 1. - С. 322.

19. Филимонова Ю.В. Арсентьева Д.Д. Повышение эффективности производства на основе применения инструментов концепции «бережливое производство» // Вестник Ангарского государственного технического университета. -2017 . - № 11. - С. 283-289.

20. Ахмадеева Г.Ч. Система снижения производственных потерь на предприятиях машиностроения: автореф. дис. ... канд. экон наук. - Казань, 2011. - 31 с.

\section{References}

1. Monden Y. Toyota production system: Practical approach to production management (Russ. ed.: Monden Ia. "Toyota". Metody effektivnogo upravleniia. Eds. A.R. Benediktov, V.V. Motylev, Moscow, Ekonomika, 1989, 228 p.).

2. Wader M. Lean tools 2005 a pocket guide to implementing lean practices (Russ. ed.: Veider M. Instrumenty berezhlivogo proizvodstva: mini-rukovodstvo po vnedreniiu metodik berezhlivogo proizvodstva. Moscow, Al'pina Pablisher, 2015, 116 p.).

3. Abrosimova A.A. Razvitie metodov berezhlivogo proizvodstva na promyshlennykh predpriiatiiakh [Development of lean manufacturing methods in industrial enterprises]. Abstract of PhD thesis. Nizhnii Novgorod, UNN, 2013, 23 p.

4. Klochkov Iu.P. Primenenie kontseptsii Lean dlia povysheniia proizvoditel'nosti truda na primere OAO "KAMAZ" [Application of the lean concept to increase labor productivity on the example of OAO KAMAZ]. Effektivnye protsessy - vysokaia proizvoditel'nost'. Proc. Int. Forum. Kazan, 2011. Available at: https://docviewer.yandex.ru/view/935952/?* (accessed 20.09.2020).

5. Panteleev D.N. Obespechenie konkurentosposobnosti predprinimatel'skikh struktur na osnove konkurentsii berezhlivogo proizvodstva [Ensuring the competi- 
tiveness of entrepreneurial structures based on the competition of lean production]. Abstract of PhD thesis. Izhevsk, Institute of Economics, Ural Branch of the Russian Academy of Sciences, 2007, $24 \mathrm{p}$.

6. Shiliaeva E.V. Otsenka povysheniia konkurentosposobnosti rossiiskikh promyshlennykh predpriiatii pri vnedrenii sistemy berezhlivogo proizvodstva [Assessing increase in Russian industrial enterprises competitiveness following implementation of a lean manufacturing system]. Abstract of PhD thesis. Moscow, HSE, 2017, $31 \mathrm{p}$.

7. Boltacheva N.R. Berezhlivoe proizvodstvo kak metod povysheniia effektivnosti proizvodstva na predpriiatii [Lean manufacturing as a method of increasing production efficiency at an enterprise]. SCIENCE TIME, 2015, no. 8 (20), pp. 26-29.

8. Womack J., Jones D. Lean thinking: banish waste and create wealth in your corporation (Russ. ed.: Vumek D.P., Dzhons D.T. Berezhlivoe proizvodstvo. Kak izbavit'sia ot poter' i dobit'sia protsvetaniia vashei kompanii. Moscow, Al'pina Pablisher, 2011, 473 p.).

9. Masaaki I. Kaizen: The key to Japan's competitive success (Russ. ed.: Masaaki I. Kaidzen. Kliuch k uspekhu iaponskikh kompanii, Moscow, Al'pina Pablisher, 2011, 341 p.).

10. Klimochkin D.A., Paniavina M.L. Osobennosti primeneniia kontseptsii berezhlivogo proizvodstva $\mathrm{v}$ rossiiskikh usloviiakh [Application features of lean manufacturing concept in Russian conditions]. Sovremennoe upravlenie problemy, tendentsii i perspektivy. Proc. All-Russ. Acad. Conf. Tambov, 2018, pp. 44-49.

11. Kalinina K.R. Berezhlivoe proizvodstvo kak instrument organizatsii upravleniia proizvodstvom [Lean manufacturing as a tool for organization of production]. Aktual'nye problemy aviatsii i kosmonavtiki, 2015, no. 1, pp. 224-226.

12. GOST R ISO 10006-2005. Rukovodstvo po menedzhmentu kachestva pri proektirovanii [GOST R ISO 10006-2005. Guidelines for quality management in design]. Moscow, Federal Agency for Technical Regulation and Metrology, 2007, no. 221, 41 p.

13. Kaniukova V.P. Berezhlivoe proizvodstvo: osnovnye instrumenty i printsipy berezhlivogo proizvodstva [Lean manufacturing: Basic lean tools and principles]. Alleia nauki, 2018, no. 7 (23), pp. 642-647.

14. Surikova E.A. Povyshenie effektivnosti deiatel'nosti strukturnogo podrazdeleniia zheleznodorozhnogo transporta na osnove printsipov berezhlivogo proizvodstva [Improving the efficiency of the railway transport structural unit on the principles of lean production]. Problemy ekonomiki i menedzhmenta, 2015, no. 1(41), pp. 73-79.

15. Natsional'nyi proekt "Proizvoditel'nost' truda i podderzhka zaniatosti" [National project "Labor productivity and employment support"]. Available at: https://www.economy.gov.ru/material/directions/nacionalnyy_proekt_proizvoditelno st_truda_i_podderzhka_zanyatosti/ (accessed 20.09.2020).

16. Ustav Avtonomnoi nekommercheskoi organizatsii "Federal'nyi tsentr kompetentsii v sfere proizvoditel'nosti truda" [Charter of the Autonomous Noncommercial Organization "Federal Center of Competence in the sphere of Labour Productivity"]. Moscow, Federal Center of Competence in the sphere of Labour Productivity, 2019, 15 p. 
17. GOST R 56020-2014. Natsional'nyi standart Rossiiskoi Federatsii. Berezhlivoe proizvodstvo. Osnovnye polozheniia i slovar' [GOST R 56020-2014. National standard of the Russian Federation. Lean production. Fundamentals and vocabulary]. Moscow, Rosstandart, 2014, no. 431, 32 p.

18. Ermashkevich N.S. Profil' biznesa kompanii i aktivy, ego sostavliaiushchie [Company business profile and assets included in it]. Sovremennye problemy nauki $i$ obrazovaniia, 2013, no. 1, 322 p.

19. Filimonova Iu.V., Arsent'eva D.D. Povyshenie effektivnosti proizvodstva na osnove primeneniia instrumentov kontseptsii "berezhlivoe proizvodstvo" [Productive efficiency increase based on application tools of the concept "lean production"]. Vestnik Angarskogo gosudarstvennogo tekhnicheskogo universiteta, 2017, no. 11, pp. 283-289.

20. Akhmadeeva G.Ch. Sistema snizheniia proizvodstvennykh poter' na predpriiatiiakh mashinostroeniia [System for reducing production losses at mechanical engineering enterprises]. Abstract of $\mathrm{PhD}$ thesis. Kazan, 2011, 31 p.

Оригинальность $85 \%$

Получено 27.10.2020 Принято 23.11.2020 Опубликовано 31.03.2021

\title{
V.S. Patrushev \\ ANALYSIS OF IMPLEMENTATION OF LEAN PRODUCTION TOOLS (THE CASE OF SORBENT JSC)
}

\begin{abstract}
The article reveals the features of applying methods and tools of lean production on the example of foreign and domestic enterprises. Theoretical and practical aspects of the methodology are considered. The successful experience of implementing lean production methods at Sorbent JSC, Russia, is described. The paper addresses the methods of increasing an economic component of the enterprise by inclusion of personnel in the streams of creating consumer value and increasing personal and group responsibility for the results of their work through the participation of employees in working groups. An approach has been developed that combines lean production tools and enterprise modernization processes; arrangements were made to automate individual jobs. The economic effect of using and implementing lean production tools is described on the example of Sorbent JSC and the dynamics of its production processes. It shows clear examples of increasing production volume and output, reducing cycle time and assembly time of certain parts, lowering work in progress (WIP), reducing the process time, using the value stream map, structuring the logistics of delivering raw materials to the enterprise, popularizing knowledge to boost performance of employees and management staff. As part of the national project "Labor productivity and employment support", lean production tools were introduced at the pilot site of the enterprise: visualization, information centers, a project management stand, the structure of management processes having been improved. Problems are formulated and ways to solve them are demonstrated when implementing the principles of lean production at Sorbent JSC.
\end{abstract}

Keywords: lean production, economy, labor productivity, methods and tools of lean production, efficiency.

Vladimir S. Patrushev - Manager of ORPS, Sorbent JSC; Postgraduate Student, Department of Management and Marketing, Perm National Research Polytechnic University, e-mail: patrushev94@yandex.ru.

Received 27.10.2020 Accepted 23.11.2020 Published 31.03.2021 